\title{
Settling distances of benthic invertebrates in a sediment mobilization simulation in semi-natural flumes
}

\author{
Maria Cristina BRUNO,${ }^{1 *}$ Bruno MAIOLINI, ${ }^{1}$ Mauro CAROLLI ${ }^{2}$
}

${ }^{1}$ Sustainable Agro-ecosystems and Bioresources Department, Fondazione Edmund Mach, IASMA Research and Innovation Centre, Via E. Mach 1, I-38010 San Michele all'Adige (TN); ${ }^{2}$ Department of Civil, Environmental and Mechanical Engineering, University of Trento, Via Mesiano 77, I-38100 Trento, Italy

*Corresponding author: cristina.bruno@fmach.it

\begin{abstract}
Drift time and distance depend on the ability of the drifting invertebrates to alter their body posture or by swimming, and these behaviours may change according to the local hydraulic environment, resulting in different distances travelled before exiting the drift. Such drift and settlement-mediated invertebrate movement determine dispersion processes and ultimately generates distribution patterns within streams. We conducted an experiment in an open-air, artificial flume system directly fed by an Alpine stream, where we disturbed the sediment in the flumes, inducing catastrophic drift in the benthic community, and then assessed the settlement distances of benthic invertebrates. For each flume, we collected drift samples by disturbing the substrate at $1.5 \mathrm{~m}$ intervals, at increasing distance from the downstream end, for a total of 7 disturbances and a maximum settling distance of $10 \mathrm{~m}$ in each flume, with five replicates (i.e., five flumes) for each disturbance. The disturbances induced a massive catastrophic drift in Ephemeroptera, Plecoptera and Trichoptera, always higher than the behaviourally-occurring basedrift. The Settling Index calculated over the total drift collected at each distance increased with increasing distance, and after $10 \mathrm{~m}, 90 \%$ of the drifting animals had settled. Evenness and taxa richness progressively decrease with increasing settling distance. All drifting taxa were represented mainly by young instars. We used the drift collected at $1 \mathrm{~m}$ from the disturbance to standardize the remaining samples, based on the assumption that $1 \mathrm{~m}$ is not a distance long enough to allow animals to settle at that water velocity. We calculated the percentage of possible drifters which settled by computing a Settling Index for each taxon. The drifting taxa listed by decreasing Settling Index scores were Epeorus $s p$., Rhithrogena semicolorata, Isoperla $s p p$., Sericostoma $s p p$., Ecdyonurus $s p p$., Nemoura spp., Leuctra spp., Baetis spp., Hydropsyche spp., Rhyacophila spp. We have shown, in accordance with numerous other studies, that entrained EPT nymphs travel only short distances before returning to the substratum, and that the actual distance travelled while drifting and the total time spent in drift varies between species. The results of this study can provide suggestions to assess taxon-specific availability to colonization which generates distribution patterns within streams and, on a smaller scale (1.e., flume simulations), our results can be extrapolated to other studies conducted in artificial flumes, or to support evidences from field studies.
\end{abstract}

Key words: Invertebrate drift; downstream dispersion; EPT; larval settlement.

Received: September 2015. Accepted: October 2015.

\section{INTRODUCTION}

Drift regulates densities, dispersal, and life cycles of benthic invertebrates in streams (Brittain and Eikeland, 1988; Céréghino and Lavandier, 1998; Maier, 2001; Mochizuki et al., 2006). In temperate streams, invertebrate drift is represented mainly by larval stages of Ephemeroptera, Diptera Simuliidae and Chironomidae, Plecoptera and Trichoptera, which are the most common benthic taxa in such habitats (Brittain and Eikeland, 1988; Hieber et al., 2003). Catastrophic drift (sensu CULP et al., 1985 ) is usually associated with flood conditions, during which the substrate is physically disturbed. Drift time and distance depend on the ability of the drifting invertebrates to alter their body posture or swimming, and these behaviors may change according to the local hydraulic environment. Similarly, the hydraulic conditions and the near-bed flows may initially influence the ability of organisms to set- the by reducing access to particular areas of the streambed (Fonseca and Hart, 2001; Oldmeadow et al., 2009 and references therein). Thus, distances travelled before exiting the drift are determined by the physical constraints imposed by the hydraulic environment on the morphological and mechanical swimming abilities of organisms, and the decisions individuals make regarding whether to terminate or prolong drift (Oldmeadow et al., 2009). In the end, invertebrate movement, mediated by drift travelling distances and settling abilities, generates distribution patterns within streams (Oldmeadow et al., 2009).

Today, experimental flumes of different typology have become a common tool to study the responses of biological communities to physical, chemical, hydrological manipulations, using behavioral and catastrophic drift as the measured response and based on the hypothesis that any invertebrate showing an immediate avoidance or displace- 
ment reaction would rapidly drift (Holomuzki and Biggs, 2000; Imbert and Perry, 2000; Suren and Jowett, 2001; Mochizuki et al., 2006; Carolli et al., 2012; Fenoglio et al., 2013; Bruno et al., 2013, 2016). Although drift catches in these simulations were often high, it is difficult to assess the significance of these responses, since if a high proportion of the benthos enters the drift for a short period of time, the drifting invertebrates may have originated from the area immediately downstream from the disturbance and could have returned rapidly to the benthos and thus not have been caught. Alternatively, if a low proportion of the benthos enters the drift, and the drifting invertebrates do not return rapidly to the streambed, the animals caught in the drift sampler may have drifted over a long distance and originated from an extensive area downstream from the disturbance point. This issue cannot be resolved until more is known about the distance travelled and/or the time spent in the drift by the different taxa present in the flumes, as already noted by Elliott (2002).

In this study we describe the results of a manipulative experiment where we disturbed the sediment in a set of artificial flumes inducing catastrophic drift in the benthic community, and then assessed the settlement distances of benthic invertebrates, particularly EPT. We examined the invertebrates drift distances and the rate at which they return to the substrate, based on the assumption that the differences in drift abundance/composition recorded between the samples collected at a given distance $\mathrm{x}$ from the disturbance and those collected at the upstream distance $x+1$ are presumably due to those taxa/individuals which settle on the substrate between $x$ and $x+1$. The main questions investigated in our research were the following: i) does the community settle along a distance gradient, or after a certain drifting distance threshold?; ii) which are the drifting and settling tendencies for the EPT taxa present in benthic communities?; iii) when collecting drift after a certain distance from disturbance, which is the minimum distance threshold after which a significant number of individuals/taxa have settled?

The general contribution of our simulations to the understanding of invertebrate drift is to help assessing the relative importance of potential larval supply (i.e., drifting invertebrates) and post-settlement persistence in generating distribution and abundance patterns in streams after catastrophic events.

\section{METHODS}

\section{Experimental design}

The experiments were conducted in a set of metal flumes situated on the riparian zone of the Fersina Stream ( $46^{\circ} 04^{\prime} 32^{\prime \prime} \mathrm{N}, 11^{\circ} 16^{\prime} 24^{\prime \prime} \mathrm{E}$ ) at $577 \mathrm{~m}$ asl. The Fersina Stream is a $2^{\text {nd }}$ order stream, originating at an altitude of 2005 m, and joins the Adige River at Trento (Trentino
Province, Northeastern Italy) at $191 \mathrm{~m}$ asl. It is a snowmeltfed gravel-bed stream, approximately $37 \mathrm{~km}$ long, with a $171 \mathrm{~km}^{2}$ watershed, receiving the contribution of numerous small streams that descend from lateral valleys. The mean annual discharge of the Fersina in 2012, measured at its joining to the Adige in Trento, was approximately $3 \mathrm{~m}^{3} \mathrm{~s}^{-1}$ (downloaded from http://www.floods.it/public/PreDati. php). The experimental setting consists of five $20 \mathrm{~m}$ long, $30 \mathrm{~cm}$ wide metal flumes (bottom surface area: $6.0 \mathrm{~m}^{2}$ ); flumes A, B, C are $30 \mathrm{~cm}$ deep; flumes D and E are $50 \mathrm{~cm}$ deep. Each flume has an adjustable longitudinal slope and feeding discharge. They are connected to a loading tank that is directly fed by water diverted from the stream, and benthic invertebrates can freely colonize the flumes by downstream drift and egg deposition. The flumes are filled to the same depth with two layers of cobbles of approximately $10 \mathrm{~cm}$ diameter, and a deposited fine layer of silt/sand/gravel has collected around the stones. The flumes had been run continuously at a baseflow of $0.005 \mathrm{~m}^{3} \mathrm{~s}^{-1}$, velocity $0.4 \mathrm{~m} \mathrm{~s}^{-1}$, from the beginning of April 2013 for other simulations (Bruno et al., 2016), and reset on September $10^{\text {th }}$, and the flumes left undisturbed until the experiment day, occurring on $22^{\text {nd }}$ October 2013.

\section{Biological sampling}

Two benthic samples were collected one day before the experiments in each of the flumes (downstream of the inlet, upstream of the outlet) with a Hess sampler (23.5 $\mathrm{cm}$ diameter, $100 \mu \mathrm{m}$ mesh). During the experiment, the upstream entrance to the flumes was netted-off to prevent incoming drift from upstream. Drift samples were collected by filtering the whole volume of water leaving the flumes with $350 \mu \mathrm{m}$ mesh drift nets inserted at the downstream end of each flume. We entrained benthic invertebrates in the flow by manually moving the substratum, as uniformly as possible, inside a frame of $22 \times 22 \mathrm{~cm}$ (surface $0.0484 \mathrm{~m}^{2}$ ). The disturbance technique has been used previously in similar studies (McLay, 1970; Larkin and McKone, 1985; Lancaster et al., 1996).

Basedrift (i.e., behavioural active drift, and background passive drift occurring naturally, not associated with any disturbance events) was assessed by filtering each flume for $60 \mathrm{~min}$ prior to conducting the simulations. For each flume, we collected drift samples by disturbing the substrate at $1.5 \mathrm{~m}$ intervals, at increasing distance from the downstream end: $1 \mathrm{~m}, 2.5 \mathrm{~m}, 4 \mathrm{~m}, 5.5 \mathrm{~m}, 7 \mathrm{~m}, 8.5 \mathrm{~m}$ e $10 \mathrm{~m}$. A total of 7 disturbances were created in each flume, with five replicates (i.e., five flumes) for each disturbance. Disturbance lasted $1 \mathrm{~min}$, and drifting invertebrates were collected for $10 \mathrm{~min}$ from the beginning of each disturbance. Each disturbance was performed $30 \mathrm{~min}$ after the previous one, each set of 7 samples took $3 \mathrm{~h}$ and $10 \mathrm{~min}$ to be completed. Samples in the different flumes were staggered by $5 \mathrm{~min}$. Sampling took place from 10 
a.m. to 1.30 p.m. After collection, all samples were fixed on the field in $75 \%$ ethanol. All samples were sorted in the laboratory and organisms identified to the lowest possible taxonomic level following Campaioli et al., 1994, 1999; Fochetti et al., 2009. Several early instars of insects could not be identified further than family; we classified all nymphs as juvenile nymphs (first and second instars, size generally $<0.5 \mathrm{~cm}$ ) or nymphs (later instars, up to mature nymphs). We excluded adult insects from the analysis, since they are accidentally present in drift. For the analysis, we focused only on Ephemeroptera, Plecoptera and Trichoptera (EPT) which are often good indicators of environmental conditions in streams (Lenat, 1988; Barbour et al., 1996; Resh and Jackson, 1993), and we chose to use only the EPT taxa whose total density in drift was $\geq \%$, i.e., the Ephemeroptera Baetis spp., Epeorus spp., Ecdyonurus spp., Rhithrogena spp., the Trichoptera $H y$ dropsyche spp., Sericostoma spp., Rhyacophila spp., the Plecoptera Nemoura spp., Leuctra spp., Isoperla spp.

\section{Statistical analysis}

Invertebrate drift densities were expressed as number of individuals ( $\mathrm{N}$. ind.) $\mathrm{m}^{-3}$ by adjusting the numbers of collected individuals for the filtered volume of water, calculated based on sampling time (600 s) and discharge $\left(0.005 \mathrm{~m}^{3} \mathrm{~s}^{-1}\right)$.

\section{Changes in drifting community over drifting distances}

Firstly, as preliminary step, we assessed if the flumes had been colonized by the same benthic communities, i.e., if the drift samples collected in the different flumes were replicates. In fact, if the density and composition of the drift source (i.e., the benthos) were similar among flumes, then drift abundances, and their differences over distance from the disturbance, could be used for the purpose of this research without bias. Benthic density was measured by calculating the mean densities per flume, and expressed as $\mathrm{N}$ ind. $\mathrm{m}^{-2}$ by testing for significant differences in densities of each taxon and of the entire community overall (one-way univariate and multivariate ANOVA, factor FLUME), and in composition of the benthic community (one-way PERMANOVA, factor FLUME). Secondly, because the analysis showed that the flumes had indeed been colonized by similar assemblages (see results for details), we used the drift densities (calculated as the total number of animals in the drift at each distance from the disturbance over the whole sampling time interval, and expressed and $\mathrm{N}$ ind. $\mathrm{m}^{-}$ ${ }^{3}$ ) for the remaining analysis. Drift densities were $\log (x+1)$ transformed, and the Bray-Curtis index was used to calculate the similarity matrix for all PERMANOVA analyses. We tested if the drift samples collected in the different flumes were replicates, by testing for significant differences in density of each drifting taxon (one-way PERMANOVA, factor FLUME), and in composition of the drifting community (one-way PERMANOVA, factor FLUME), among flumes. Thirdly, we assessed the effectiveness of our simulations by testing for significant differences in abundance and composition (non parametric Kruskall-Wallis test, and PERMANOVA, respectively) between drift samples conducted during the manipulations and the basedrift for each distance and for each taxon, on a $\log (\mathrm{x}+1)$ transformed data matrix. Fourthly, we investigated drifting and settling distances for the entire community. We looked for patterns in the drift at different distances from the source in the unconstrained multivariate space using the Principal coordinates analysis (PCO, also known as MDS), and we assessed significant differences in abundance and composition (oneway ANOVA and PERMANOVA, respectively) followed by pairwise comparisons (HSD Tukey's test and PERMANOVA pairwise comparisons, respectively). To evaluate changes in community composition with increasing settling distance (i.e., distance from the disturbance), we used a ranked species cumulative abundance plot to visualize species abundance distributions, and the Bray-Curtis dissimilarity index calculated comparing the most distant drift sample (10 $\mathrm{m}$ from disturbance) with progressively closer ones.

\section{Taxa-specific responses}

Based on the working hypothesis that we manually displaced a portion of the residing benthos of approximately the same amount/composition for each disturbance, and that part of the drifting organisms would return to the substrate while travelling along the flumes, and hence would not be collected at the flume outlet, we calculated a settling index for each taxon and for the overall community (i.e., calculating over the total drift) at each distance. We used the drift collected at $1 \mathrm{~m}$ from the disturbance to standardize the remaining samples, based on the assumption that $1 \mathrm{~m}$ is not a distance long enough to allow animals to settle at that water velocity (based on the travelling time and distances reviewed in Elliot, 2002). We calculated the percentage of possible drifters as follows:

$S I_{d}=100-\left(\mathrm{dr}_{\mathrm{d}} / \mathrm{dr}_{1 \mathrm{~m}} * 100\right)$

where

$\mathrm{d}=$ distance from the disturbance;

$\mathrm{dr}=\mathrm{drift}$ abundance (expressed as $\mathrm{n}$ ind. $\mathrm{m}^{-3}$ );

$\mathrm{dr}_{\mathrm{d}=\mathrm{drift}}$ collected at distance $\mathrm{d}$;

$\mathrm{dr}_{1 \mathrm{~m}}=$ drift collected at $1 \mathrm{~m}$.

For each taxon, we then calculated a settling index by averaging the 6 indices, as follows:

$\mathrm{SI}=$ mean $\left(\mathrm{SI}_{2.5}, \mathrm{SI}_{4}, \mathrm{SI}_{5.5}, \mathrm{SI}_{7}, \mathrm{SI}_{8.5}, \mathrm{SI}_{10}\right)$ 
For the whole drifting community, we calculated a mean settling index for drifting intervals of about $3 \mathrm{~m}$ (2.5-4 m, 4-7 m, 7-10 m). The reason behind the choice of this interval will be explained below.

Data were analyzed in Primer 6 ver. 6.1.12 (PRIMERE Ltd, 2009), and STATISTICA (data analysis software system) ver. 9.1. (StatSoft, Inc. 2010).

\section{RESULTS}

The flumes had been colonized in a similar way prior to conducting the experiment. In fact, benthic samples did not differ among flumes in species composition overall and for all pairwise comparison between flumes, nor in abundance overall and for each taxon density (Tab. 1). Hence, we could assume that the five flumes represented five replicates, and that approximately the same (in density and composition) component of the EPT assemblages was induced to drift by each manipulation. Flumes did not differ in species composition of the drifting assemblages, nor did they differ in drift density for each taxon and for the total density (Tab. 1). We therefore used the flumes as replicates in the subsequent statistical analysis.

\section{Changes in drifting community over drifting distances}

The catastrophic drift induced by manipulations differed significantly from the basedrift in composition and abundance overall and for each taxon density (Tab. 1). The ratio of the total drift collected for each sample and flume to the basedrift collected in that same flume, was always $>1$ for each flume and settling distance, and as average decreased exponentially with increasing settling distances from $126(1 \mathrm{~m}$ settling distance $)$ to $12(10 \mathrm{~m}$ settling distance) (Tab. 2). Hence, the simulations induced a massive catastrophic drift, always higher than the behaviourally-occurring basedrift, and the amount of drifting animals that did not settle, and continued drifting catastrophically decreased over distance.

The catastrophic drift when ordinated in a principal coordinates analysis showed distinct composition according to a gradient of decreasing distance from disturbances (i.e., with decreasing settling distances) (Fig. 1) on the primary axis, which explained $69.7 \%$ of the total variation; the secondary axis, which explained $9.7 \%$ of the total variation, represented a gradient due the drift collected after the invertebrates had $10 \mathrm{~m}$ to settle. Drift densities significantly changed with distance (Tab. 1, Fig. 2), with the drift collected at increasing settling distances being respectively 1.4 (drift collected after $2.5 \mathrm{~m}), 2.4(4 \mathrm{~m}), 3.7(5.5 . \mathrm{m}), 5.5(7$ $\mathrm{m}), 6.6(8.5 \mathrm{~m})$, and $9.6(10 \mathrm{~m})$ times less abundant than the one collected after $1 \mathrm{~m}$. All taxa decreased in density with increasing settling distance (Fig. 3).

The drift abundance and composition showed a sig-

Tab. 1. Result of the statistical analyses.

\begin{tabular}{|c|c|c|c|c|c|c|c|c|c|c|}
\hline & \multirow[b]{2}{*}{ Factor } & \multirow[b]{2}{*}{ df } & \multicolumn{2}{|c|}{ PERMANOVA } & \multicolumn{3}{|c|}{ Univariate ANOVA } & \multicolumn{3}{|c|}{ Multivariate ANOVA } \\
\hline & & & Pseudo-F & $\begin{array}{c}\text { P (perm) } \\
\text { overall }\end{array}$ & P pairwise & df & $P$ & df & F & $\mathbf{P}$ \\
\hline Benthos & FLUME & 4 & 0.97 & 0.467 & Always $>0.05$ & 4 & $\begin{array}{l}\text { Always }>0.05 \\
\text { for each taxon }\end{array}$ & 20 & 2.25 & 0.21 \\
\hline Drift & FLUME & 4 & 1.50 & 0.175 & Always $>0.05$ & 4 & $\begin{array}{l}\text { Always }>0.05 \\
\text { for each taxon }\end{array}$ & 44 & 1.96 & $0.005^{* *}$ \\
\hline Drift & $\begin{array}{l}\text { Basedrift } v s \\
\text { catastrophic drift }\end{array}$ & 1 & 40.26 & $0.001 * *$ & & & & 28 & 8.78 & $<0.001 * * *$ \\
\hline Drift & Drifting distance & 6 & 6.81 & $0.001 * *$ & & & & 60 & 2.44 & $<0.001 * * *$ \\
\hline
\end{tabular}

$d f$, degree of freedom; $* P=0.01$ to 0.05 (significant); $* * P=0.001$ to 0.01 (very significant); $* * * P<0.001$ (extremely significant).

Tab. 2. Ratio of total drift collected during the experiment to basedrift.

\begin{tabular}{lcccccc} 
& Flume A & Flume B & Flume C & Flume D & Flume E & Mean \\
Drift $1 \mathrm{~m}$ & 106 & 205 & 39 & 160 & 121 & 126 \\
Drift $2.5 \mathrm{~m}$ & 80 & 193 & 27 & 100 & 84 & 97 \\
\hline Drift $4 \mathrm{~m}$ & 42 & 48 & 13 & 65 & 73 & 48 \\
Drift $5.5 \mathrm{~m}$ & 36 & 48 & 9 & 41 & 35 & 34 \\
\hline Drift $7 \mathrm{~m}$ & 21 & 55 & 9 & 22 & 11 & 13 \\
Drift $8.5 \mathrm{~m}$ & 21 & 18 & 7 & 16 & 8 & 18 \\
\hline Drift $10 \mathrm{~m}$ & 16 & 14 & 5 & & 12 \\
\hline
\end{tabular}


nificant change over distance overall (Tab. 1), and pairwise comparisons in composition (Tab. 3) indicate that samples collected with 1 and $2.5 \mathrm{~m}$ settling distance were similar but differed from all those collected with longer drifting distances. These samples, collected from 4 to 10 $\mathrm{m}$ from disturbances, differed among groups including 3 $\mathrm{m}$ of travelling distance, starting from $4 \mathrm{~m}$ (for instance, drift samples collected at $10 \mathrm{~m}$ were similar in composition only to those collected at 8.5 and $7 \mathrm{~m}$; samples collected at $8.5 \mathrm{~m}$ only to those collected at 7 and $5.5 . \mathrm{m}$; samples collected at $7 \mathrm{~m}$ only to those collected at 5.5 and $4 \mathrm{~m}$; and samples collected at $5.5 \mathrm{~m}$ were similar only to those collected at $4 \mathrm{~m}$ ).

The Settling Index calculated over the total drift collected at each distance increased with increasing distance (Tab. 3), and after $10 \mathrm{~m}, 90 \%$ of the drifting animals had settled. More interestingly, the moving SI average, calculated for drifting intervals with no differences in composition, i.e., of about $3 \mathrm{~m}$ (2.5-4 m, 4-7 m, 7-10 m), increases linearly $\left(\mathrm{R}^{2}=0.967\right)$ with distance from 43 ind. $\mathrm{m}^{-3}$ for 2.5 $4 \mathrm{~m}$ to 71 ind. $\mathrm{m}^{-3}$ for $4-7 \mathrm{~m}$, to 85 ind. $\mathrm{m}^{-3}$ for $7-10 \mathrm{~m}$.

The ranked species cumulative abundance plot (Fig. 4) shows a progressive decrease in evenness and taxa richness with increasing distance from the disturbance (i.e., less taxa reached the end of the flume, and they are less equitably- distributed because several individuals reached the bottom), and the Bray-Curtis dissimilarity increases linearly $\left(\mathrm{R}^{2}=0.98\right)$ when comparing the drift with no settling $(1 \mathrm{~m}$ from disturbance) with progressively increasing settling distance (Tab. 3), i.e., the longer the settling distance, the more dissimilar the drifting communities become, because more taxa and individuals regain the bottom.

\section{Taxa-specific responses}

The taxa with highest total catastrophic drift were, in decreasing order: Baetis spp. ( $40.5 \%$ of the total, and representing $42.8 \%$ of the benthic community as assessed with kick sampling), Hydropsyche spp. (36.6 \%of catastrophic drift, $26.4 \%$ of benthos), Nemoura spp. (8.5\% and $10.3 \%)$, Leuctra spp. (7.2 \% and $7.1 \%)$, Sericostoma spp. $(2.0 \%$ and $1.3 \%)$, Epeorus sp. (1.2\% and 5.2\%), Isoperla spp. (1.1\% and 1.3\%), Ecdyonurus spp. (1.1\% and $1.8 \%)$, Rhithrogena semicolorata (1\% and $2.7 \%)$, Rhyacophila spp. (0.8\% and 1.0\%). All taxa (except Leuctra spp. for which the percentage of juveniles could not be determined, since we did not identify the specimens to the species level, and the genus varies in size, even at the late larval stage) were represented by mainly young instars, whereas the percentage of young instars present in the benthic assemblages was generally lower (Tab. 4), es-

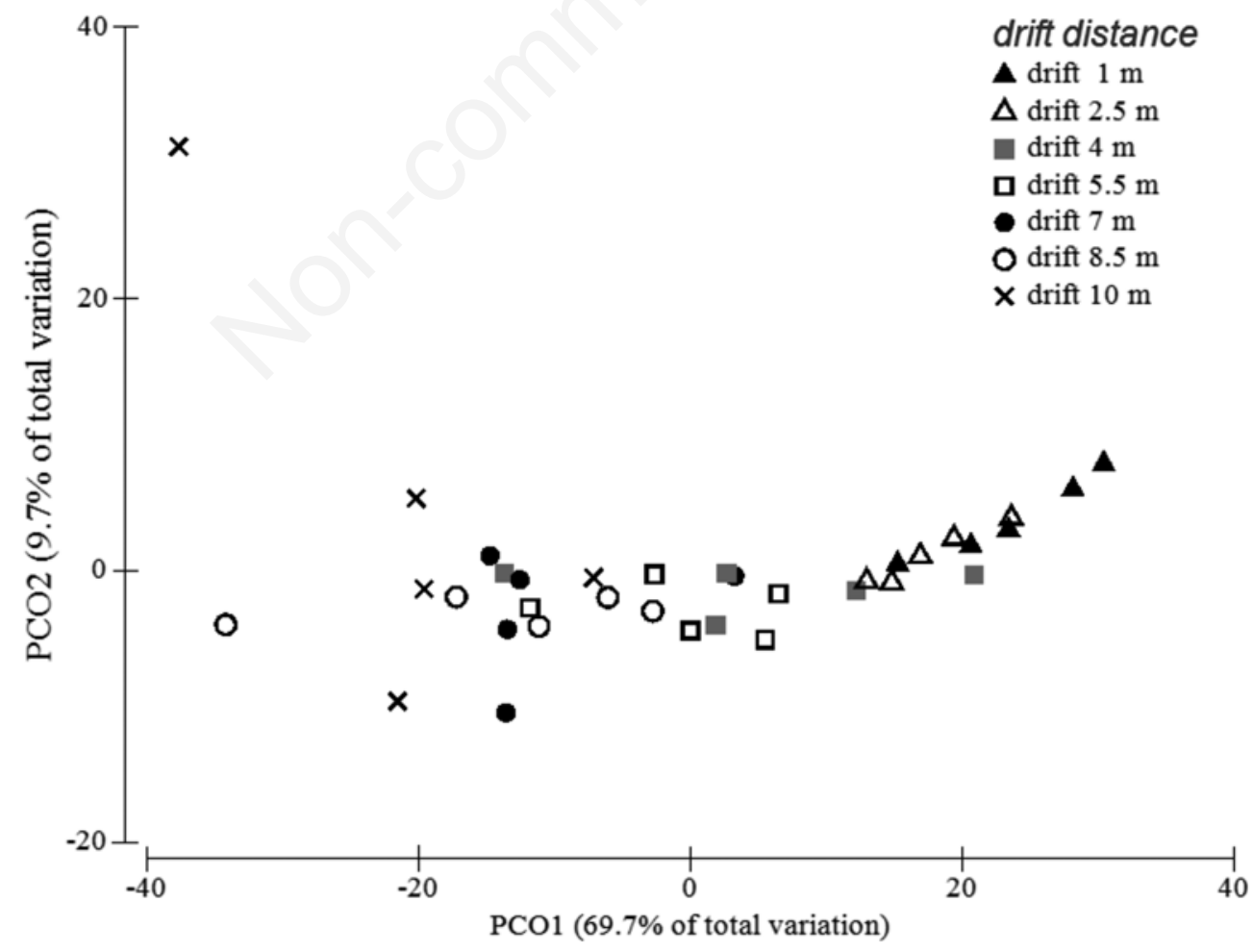

Fig. 1. Principal coordinates analysis based on Bray-Curtis Similarity Index of drifting invertebrate communities collected at each distance, for the five replicates (i.e., flumes). Data $\log (\mathrm{x}+1)$ transformed. 
pecially for Heptageniidae and all Trichoptera except Rhyacophilidae. For all taxa, the percentage of young larval stages drifting during basedrift was very high, representing about $100 \%$ of the total, with the exception of Epeorus sp., which had a similar and very low percentage of young larval stages drifting with baseflow and during the catastrophic event (Tab. 4). The comparative analysis of the ratio of catastrophic drift to basedrift, the mean catastrophic drift, the drift for each sample, the mean basedrift, the mean settling index and the settling index for each increasing distance (Tab. 4, Figs. 3 and 5) provides information on the drifting behavior and settling ability of each taxon. The taxa with settling index scores in decreasing order were (Tab. 4): Epeorus sp., Rhithrogena semicolorata, Isoperla spp., Sericostoma spp., Ecdyonurus spp., Nemoura spp., Leuctra spp., Baetis spp., Hydropsyche spp., Rhyacophila spp.

Baetis spp. has a very high drift rate, both behavioral (basedrift) and catastrophic, with comparable drift rates (in fact, the catastrophic drift was only 16 times higher than the basedrift), and catastrophic drift decreases exponentially $\left(\mathrm{R}^{2}=0.9965\right)$. The mean settling index scores 70 , and increases linearly $\left(\mathrm{R}^{2}=0.9271\right)$ with increasing settling distances, suggesting a strong ability to settle. When the set-

Tab. 3. $\mathrm{P}$ values for pairwise tests, PERMANOVA factor drift distance fixed, average Bray-Curtis dissimilarity with sample $1 \mathrm{~m}$, sand ettling index.

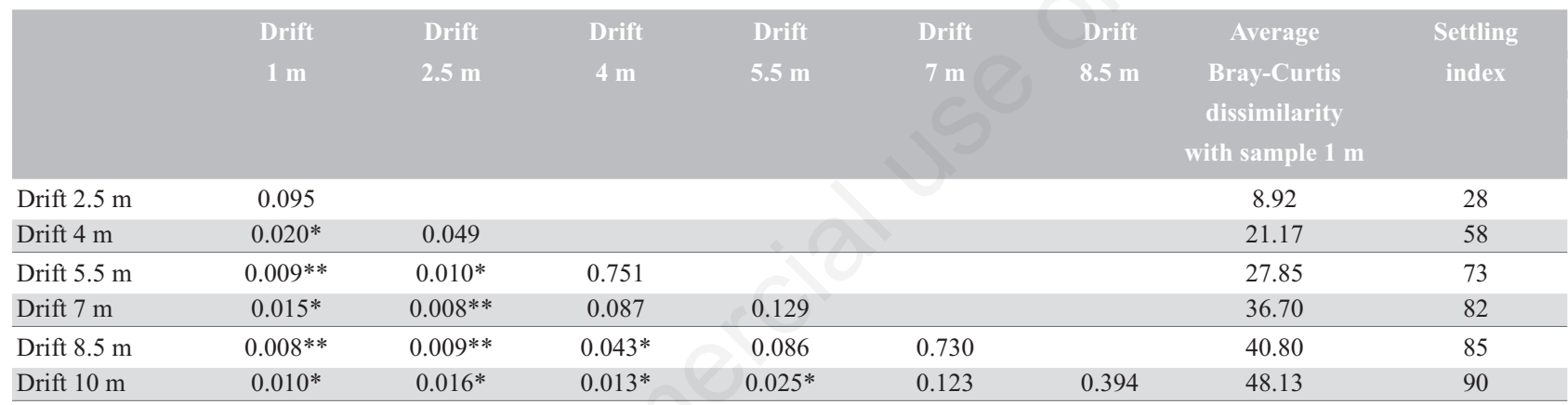

$* P=0.01$ to 0.05 (significant); $* * P=0.001$ to 0.01 (very significant); $* * * P<0.001$ (extremely significant).

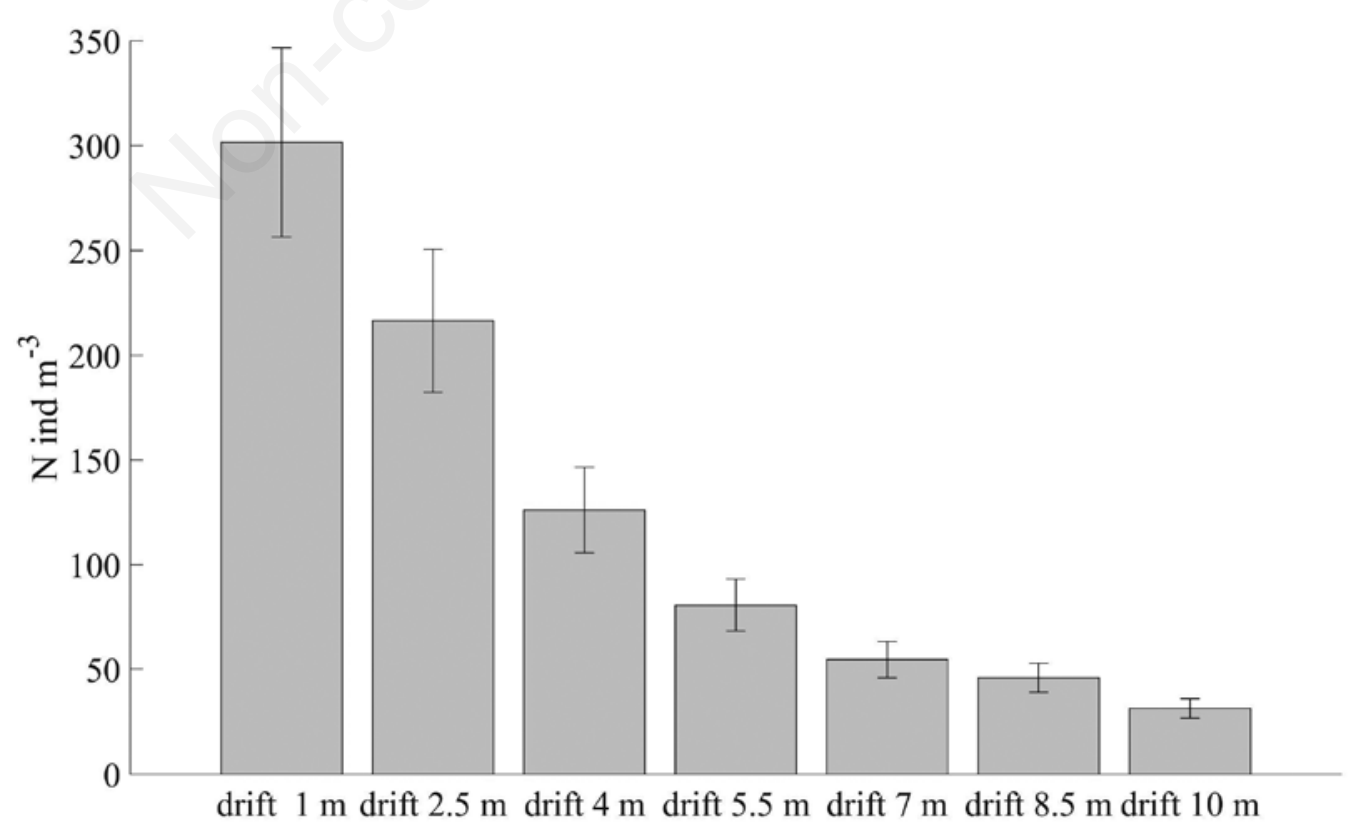

Fig. 2. Total drift for each settling distance (calculated as the sum of the mean value over five replicates for each taxon). Whiskers: standard error of the mean. 
tling distance is $10 \mathrm{~m}$, only $11 \%$ of the animals (as recorded in the $1 \mathrm{~m}$ sample) are still drifting. Hydropsyche spp. has a very low basedrift (does not tend to drift behaviourally), but very high rates of catastrophic drift (about 448 times the basedrift). The mean settling index scores 67 , very similar to Baetis spp., but settling has a slightly weaker correlation than Baetis (linear regression, $\mathrm{R}^{2}=0.7788$ ), and occurs mainly for distances from $4 \mathrm{~m}$, and at a settling distance of $10 \mathrm{~m}, 9 \%$ of the animals are still drifting. The Hep- tageniidae Ecdyonurus spp., Epeorus sp. and Rhithrogena semicolorata all have low basedrift and low tendency to drift catastrophically. The ratio to basedrift is low and similar for the three taxa. The settling scores are among the highest of all taxa, with Epeorus sp. scoring 85, followed by Rhithrogena semicolorata (81) and Ecdyonurus spp. (71). Settling occurs more similarly for all distances for Epeorus sp., is more irregular for Ecdyonurus spp. but generally higher from $5.5 . \mathrm{m}$ on with a peak at $10 \mathrm{~m}$, and for

Tab. 4. Values of basedrift, catastrophic drift, ratios, settling index, percentage of juveniles over the total of each taxon, calculated as mean over 5 flumes.

\begin{tabular}{|c|c|c|c|c|c|c|c|}
\hline & $\begin{array}{l}\text { Mean } \\
\text { basedrift } \\
\text { (ind. } \mathrm{m}^{-3} \text { ) }\end{array}$ & $\begin{array}{c}\text { Mean } \\
\text { catastrophic } \\
\text { drift } \\
\text { (ind. } \mathrm{m}^{-3} \text { ) }\end{array}$ & $\begin{array}{c}\text { Ratio } \\
\text { catastrophic } \\
\text { drift to } \\
\text { basedrift }\end{array}$ & $\begin{array}{l}\text { Settling } \\
\text { index }\end{array}$ & $\begin{array}{c}\text { Juveniles } \\
\text { in drift } \\
(\%)\end{array}$ & $\begin{array}{c}\text { Juveniles } \\
\text { in basedrift } \\
(\%)\end{array}$ & $\begin{array}{c}\text { Juveniles } \\
\text { in benthos } \\
(\%)\end{array}$ \\
\hline Baetis spp. & 3.12 & 50 & 16 & 70 & 99 & 100 & 100 \\
\hline Hydropsyche spp. & 0.1 & 45 & 448 & 67 & 99 & 100 & 86 \\
\hline Nemoura spp. & 0.38 & 10 & 27 & 70 & 98 & 100 & 100 \\
\hline Leuctra spp. & 0.06 & 9 & 146 & 70 & n.a. & n.a. & n.a. \\
\hline Isoperla spp. & 0.02 & 1 & 67 & 80 & 98 & 100 & 100 \\
\hline Epeorus sp. & 0.14 & 1 & 11 & 85 & 53 & 50 & 34 \\
\hline Ecdyonurus spp. & 0.04 & 1 & 33 & 71 & 83 & 100 & 68 \\
\hline Rhithrogena semicolorata & 0.04 & 1 & 31 & 81 & 86 & 100 & 70 \\
\hline Sericostoma spp. & 0 & 2 & Not drifting & 72 & 100 & Not drifting & 90 \\
\hline Rhyacophila spp. & 0 & 1 & Not drifting & 56 & 73 & Not drifting & 67 \\
\hline
\end{tabular}

n.a., not available.

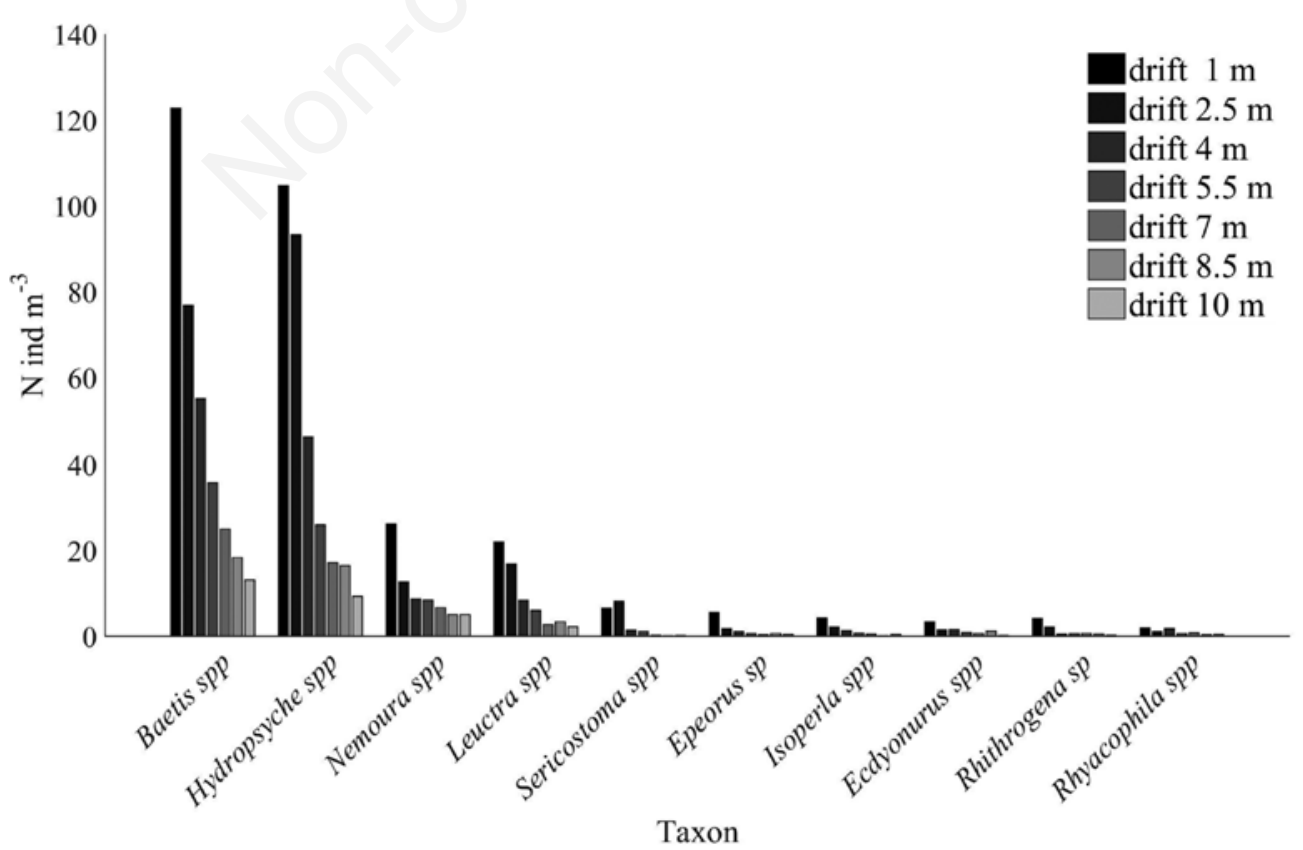

Fig. 3. Mean drift (calculated over five replicates) for each drifting taxon at each settling distance. 
Rhithrogena semicolorata increases strongly for settling distances from $4 \mathrm{~m}$; the percentage of animals still drifting at $10 \mathrm{~m}$ is respectively $7 \%, 4 \%, 21 \%$. The stoneflies Leuctra spp. and Isoperla spp. have low basedrift while Nemoura spp. has higher basedrift rates; catastrophic drift is low for Isoperla spp., higher and comparable the remaining two taxa (Tab. 4). The tendency to drift catastrophically is higher for Leuctra spp. (the ratio of catastrophic to basedrift scoring 146 for Leuctra spp., 67 for Isoperla spp., and 27 for Nemoura spp.). The settling index scores 70 for Nemoura spp. and Leuctra spp., and is higher (80) for Isoperla spp., but Nemoura spp. settling abilities do not change much with distance (settling index is similar over distances, especially from 7 to $10 \mathrm{~m}$, at $10 \mathrm{~m} \mathrm{19 \%}$ of the animals are still drifting), whereas Leuctra spp. and Isoperla spp. settle more from $4 \mathrm{~m}$ on, and especially from 7 to 10 drifting m; at $10 \mathrm{~m}$ only $10 \%$ of the animals are still present in the catastrophic drift for Leuctra spp.and Isoperla spp. The caddisflies Rhyacophila spp. and Sericostoma spp. are not present in basedrift, and have very low tendency to drift catastrophically (higher for the caddis-bearing Sericostoma spp. than the free-roaming Rhyacophila spp.). The settling index scores 72 for Sericostoma spp., and has the lowest recorded value, 56, for Rhyacophila spp. The settling behaviour differs: the settling values by distance of Sericostoma sp. was negative at $2.5 \mathrm{~m}$., indicating a higher number of drifting individuals than at $1 \mathrm{~m}$, and possibly due to the patchy distribution of this rare taxon (the drift at $2.5 \mathrm{~m}$ was variable among flumes: $15,8,8,4,4$, ind. $\mathrm{m}^{-3}$ for flumes A to E). Settling values were much higher for the remaining distances, among the highest recorded for all taxa, and almost $100 \%$ of the individuals had settled for distance over $7 \mathrm{~m}$. Rhyacophila sp. was the rarest taxon in drift and benthos, tendency to settle was highly variable with a sharp decrease at $4 \mathrm{~m}$, higher for all other distances and particularly from $8.5 \mathrm{~m}$ settling distance.

\section{DISCUSSION}

The flume system described in this study was successfully used to assess macrobenthos drift responses in previous simulations (Carolli et al., 2012, Bruno et al., 2013, 2016). Our flumes have the advantage of being freely colonized by the benthic fauna from the pristine Fersina

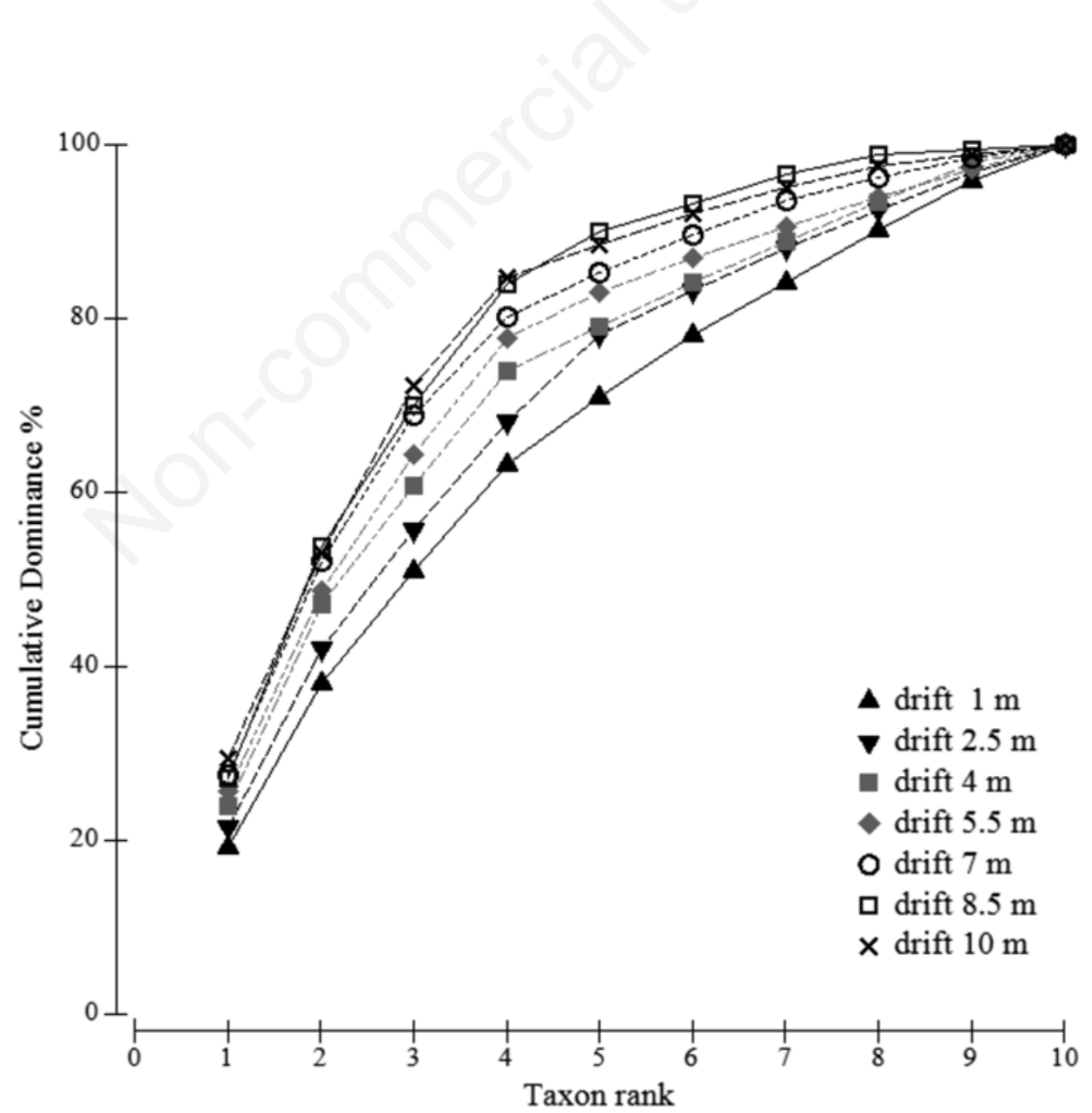

Fig. 4. Ranked taxa cumulative abundance plot for each settling distance. 
Stream via incoming drift from upstream (mainly) and egg deposition by adult (likely occurring, but never observed directly), and thus they approximately represent the benthic assemblages present in the area. The benthic communities were left undisturbed at baseflow, with natural day-light cycle and subject to natural daily changes in water temperature for a period of time which allowed colonization by benthic invertebrates, and reaching the highest taxa diversity and abundance. These near-to-natural conditions are in contrast to the small flumes in laboratory conditions (10 m or less; Allan and Feifarek, 1989; Ciborowski, 1983) used in most of the studies on drift distances, where pre-selected taxa were introduced in the drift rather than eliciting the responses of the whole naturally-occurring community. Therefore, the number of drifting nymphs involved in our experiment was higher, and the drifting community was more diverse in comparison with other studies, which often referred to observations on single or few individuals of one or few species (Allan and Feifarek, 1989; Ciborowski, 1983; Lancaster et al., 2006; Oldmeadow et al., 2009). To our knowledge, the most comparable study setting is discussed in Lancaster et al. (1996), where benthic macroinvertebrates were disturbed from the stream substrate and caught in drift nets at various distances downstream, at four selected water velocities. However, the authors investigated a very different benthic community (dominated by Plecoptera, whereas in our flumes Ephemeroptera and net-spinning Trichoptera were dominant).
The species-specific habitat requirements of benthic invertebrates determine distinctive assemblages or densities of different taxa associated with the hydraulic and geomorphic characteristics of stream mesohabitats. Our flumes are a simplified system, i.e., there are no rifflepool sequences or other mesohabitats. This obviously reduces the macrobenthos diversity by selecting more reophilic taxa, and/or taxa or life stages that can find hydraulic refuges on the bottom. However, the use of such simplified system is particularly relevant considering that Oldmeadow et al. (2009) showed that constraints on movement and settlement might be important drivers of distribution patterns within streams. The small-scale distribution patterns of some benthic taxa within a stream would therefore correspond to their drift behaviour and ability to access various hydraulic patch types, and the observed distribution patterns may reflect primarily the results of departure and settlement processes (Oldmeadow et al., 2009). The geomorphologically uniform setting of our flumes, therefore, allowed us to test only the tendency to settle and the distance travelled by drift of the investigated taxa, by removing the hydraulic variability created by riffle-pool sequences.

\section{Changes in drifting community over drifting distances}

Entrainment of zoobenthos along with sediment at high flows has a strong contribution to drift (Bond and Downes, 2003; Gibbins et al., 2005), and previous studies in artificial channels and in natural streams have con-

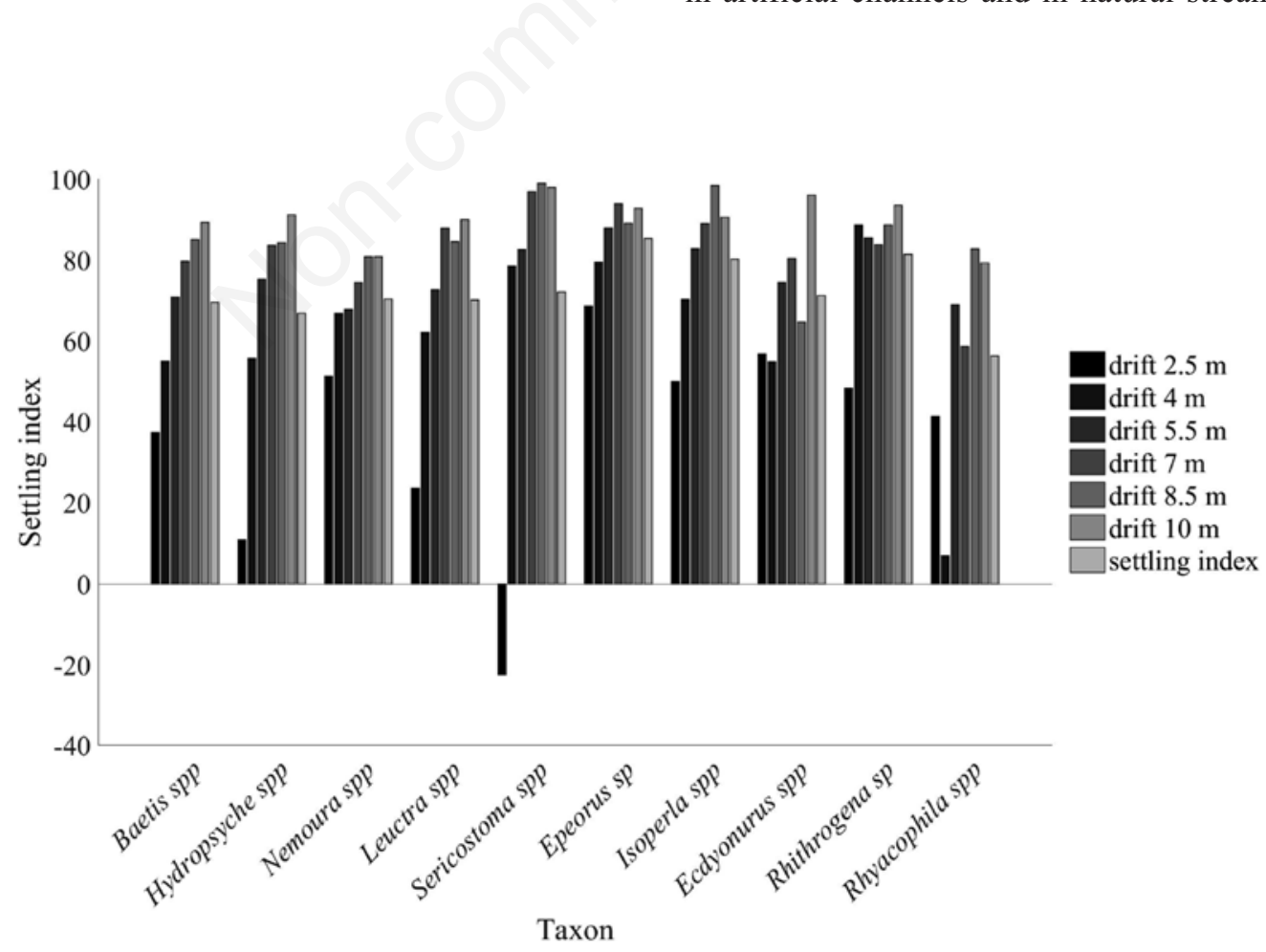

Fig. 5. Settling index for each distance and means settling index, for each taxon. 
firmed that some taxa actively exit the drift by behavioural control (Ciborowski and Corkum, 1980; Campbell, 1985; Otto and Sjökström, 1986; Allan and Feifarek, 1989; Elliott, 2002; Oldmeadow et al., 2009). Studies to assess drifting samples have been conducted by manually introducing selected larvae in artificial or natural streams and recording the numbers present in drift after a certain distance (Elliott 1971, 2002; Ciborowski and Corkum, 1980; Campbell, 1985; Otto and Sjökström, 1986; Allan and Feifareck, 1989; Oldmeadows et al., 2009); or forcing animals into the water column by disturbing the substratum and inducing catastrophic drift (McLay, 1970; Larkin and McKone, 1985; Lancaster et al., 1996). It has been argued by Elliott (2002) that by using the latter method, there is no control over the number of invertebrates entering the drift, or the different taxa in the drift. In our experiment, we chose to manually disturb the benthos nonetheless, since we were interested in evaluating the impact of settling distance on the drift densities recorded in a community in near-natural conditions. We assessed if the drift collected at the end of the $20 \mathrm{~m}$ flumes represents a correct estimate of the animals drifting as response to a disturbances, or an underestimate since a fraction of the drifting animals would have had time to settle while travelling along the flumes. The final aim was to widen the knowledge of the mechanisms involved in drift and settlement of EPT nymphs. As remarked by Oldmeaedow et al. (2009), understanding settlement processes is critical to understanding, for example, how substrate- and habitat-specific associations arise, and how dispersal influences population structure. We therefore were more interested in the distance travelled than in the time spent drifting as in other works, and in the responses of the EPT drifting community over all, rather than a single or few selected taxa. However, from the distance intervals and water velocity $\left(0.4 \mathrm{~m} \mathrm{~s}^{-1}\right)$, the drifting time of an object carried by the water flow can be estimated in $2.5,6.25$, $10,13.75,17.5,21.25,25$ seconds respectively for distances of $1,2.5,4,5.5,7,8.5,10 \mathrm{~m}$. These values are roughly comparable with published data, as drift time may be prolonged or reduced by altering body posture or by swimming, and drifting invertebrates do not behave like passive particles (Oldmeadow et al., 2009). Most benthic invertebrates drift for short distances before regaining contact with the substrate, and the distance travelled in the drift varies with different species. In studies conducted in flumes at velocities of $0.24 \mathrm{~m} \mathrm{~s}^{-1}$, most drifting invertebrates regained the bed within $1 \mathrm{~m}$ of their release point (Gibbins et al., 2007). In natural streams the drift distance of most invertebrates, and of Baetis in particular, were derived from $<2 \mathrm{~m}$ upstream of the sampling point (Townsend and Hildrew, 1976; Elliott, 2002) at velocities of respectively 0.2 and $<0.3 \mathrm{~m} \mathrm{~s}^{-1}$.

Several studies showed a clear negative exponential relationship between drift catches and distance travelled from the source of the disturbance (McLay, 1970; Elliott, 1971; Ciborowski, 1983; Larkin and McKone, 1985; Allan and Feifarek, 1989, Lancaster et al., 1996). In our flumes, every $3-\mathrm{m}$ interval (corresponding to a travelling time of approximately 7.5 seconds) a significant part of the drifting assemblage settles, creating discontinuous changes in the drift communities, which become more dissimilar and less equitably-distributed due to the different responses of the drifting taxa.

\section{Taxa-specific responses}

Most of the animals drifting in our experiment were early nymphal instars, which have been reported in other alpine streams in the same watershed of our experimental site to use the hyporheos as a refuge area to complete their development and growth (Silveri et al., 2008) or to avoid catastrophic drift during sudden discharge peaks (Bruno et al., 2009). In addition, younger instars have smaller body sizes, a factor that affects the time spent in the water columns: in laboratory studies Allan and Feifarek (1989) found that drift distance increased with decreasing body size for mayfly nymphs; the first instar of the case-building caddisfly Potamophylax cingulatus drifted more than ten times as far as the fifth instar (Otto, 1976).

According to Rader (1997), benthic invertebrate propensity to drift depends on several traits, including settling efficiency which, according to the author, depends on swimming ability, agility in regaining a foothold on the substrate, and sinking postures. The flume experiments showed that EPT taxa settle within a distance of 10 $\mathrm{m}$ and differ qualitatively in their behavioral responses during drift. This resulted in taxon-dependent settling distances, which can be compared with data from previous studies on the same genera of mayflies, stoneflies, caddisflies. Otto and Sjöström (1986), investigated drift behaviour in 25 species of mayflies, stoneflies and caddisflies in a laboratory stream. Although they recorded some differences in all orders, even between closely related species, as a general trend mayfly nymphs swam to reach the substrate as quickly as possible; stonefly nymphs prolonged the time spent in the water column by swimming, and caddisfly larvae were reluctant to swim.

For the recorded taxa of mayflies, according to Rader (1997), Baetis is a good swimmer with rapid settling capacity, whereas Heptageniidae are weak swimmers with intermediate settling efficiency, although they quickly regain a foothold when they get in contact with the substrate. Based on the values reported by Elliott (2002) for the time spent in the drift by $75 \%, 50 \%, 10 \%$ and $1 \%$ of the drifting invertebrates and the mean drifting time value, recorded in an experimental stony, fast-flowing section of stream, we can extrapolate for comparison the following travelling distances at the velocity recorded in our flumes 
(i.e., $0.4 \mathrm{~m} \mathrm{~s}^{-1}$ ): a mean $6.6 \mathrm{~m}$ for Ecdyonurus (with $75 \%$ of the animals settling at $1.9 \mathrm{~m}$ ) and $3.8 \mathrm{~m}$ for Baetis (with $75 \%$ of the animals settling at $1.1 \mathrm{~m}$ ). Oldmeadow et al., 2009 in ramped-step flume mimicking bedforms that are common in coarse-grained, high-gradient streams, recorded drifting distances of about $2 \mathrm{~m}$ for Baetis, and 4 $\mathrm{m}$ for Ecdyonurus spp. These values are well-comparable with our results, i.e., Baetis spp. starts settling immediately and regularly over increasing distances and $E c d y$ onurus spp. settles mainly from 5.5 . m onwards. Baetis spp. and Ecdyonurus spp. have behavioural control over drift through swimming bursts and posturing (i.e., maintaining a stable body orientation) (Oldmeadow et al., 2009), and Baetis spp. has been reported to actively exit the drift by orienting their body and actively swimming (Allan and Feifarek, 1989). Elliott (1971) assessed the distance travelled by drifting invertebrates in a shallow and turbulent stream, and recorded how Rhithrogena semicolorata nymphs were unable to make a firm contact with an exposed substratum in turbulent water, and returned to the bottom when they landed in zones with low water velocity, with a mean drift distance at $4.6 \mathrm{~m} \mathrm{~s}^{-1}$ of approximately $15 \mathrm{~m}$. Low velocity areas are not present in our flumes, and in fact Rhithrogena semicolorata started to settle after $4 \mathrm{~m}$, but at $10 \mathrm{~m} 21 \%$ of the nymphs were still drifting. To our knowledge, there are no studies on the settling ability or drift travelling distances for Epeorus, but this genus is reported as weak swimmers, rare in drift (catastrophic only) (Poff et al., 2006).

For caddisflies, Elliott (2002) reports a mean of $8.8 \mathrm{~m}$ travelling distance before settling for Hydropsyche (with $75 \%$ of the animals settling at $2.6 \mathrm{~m}$ ), and these values are well-comparable with our results, where $91 \%$ of $\mathrm{Hy}$ dropsyche spp. settled within $10 \mathrm{~m}$, and started settling from $4 \mathrm{~m}$. Net-spinning caddisflies often trail a silk thread to enhance their settling efficiency (Elliott, 1971; Otto and Sjöström, 1986). The remaining two caddisflies, Rhyacophila sp. and Sericostoma spp., are both rare in drift, respectively a free-living clinger preferring strong current, with weak swimming abilities, and a case-maker preferring slow currents with sandy deposits, with no swimming abilities. To our knowledge, there are no published data on entrainment distances for Sericostomatidae, but Lancaster et al. (2006) record for the limnephilid cased caddisflies Potamophylax latipennis in an experimental setting with water velocities similar to those of our flumes, a mean entrainment distance of approximately 9 $\mathrm{m}$. These values are close to those we recorded for the nymphs of Sericostoma spp., which, although rare in drift, had all settled after $7 \mathrm{~m}$ drifting.

Stoneflies have perhaps been les investigated than mayflies and caddisflies for their swimming and sinking abilities. Elliott (1971) recorded how Leuctra spp. cannot make a firm contact with an exposed substrate in turbulent water, and can only land in a zone of low water velocity, with a mean drift distance of approximately $15 \mathrm{~m}$. Lancaster et al. (1996) also found that the distance drifted by Leuctridae differed in two streams with different retention properties (i.e. physically determined drift distance), but was constant for Nemouridae and therefore drift may be under behavioural control in the nemourids but more physically determined in the leuctrids. In fact, both genera are reported as common in drift, Leuctra without swimming abilities, and Nemoura with weak swimming abilities (Poff et al., 2006). Moreover, in a low-velocity (0.1 to $0.4 \mathrm{~m} \mathrm{~s}^{-1}$ ) stream, Leuctridae had higher settling rates values than Nemouridae; the rates were similar in a higher velocity $\left(0.3\right.$ to $\left.0.8 \mathrm{~m} \mathrm{~s}^{-1}\right)$ stream (Lancaster et al., 1996). In our flumes, Leuctra spp. and Nemoura spp. had a high catastrophic drift rate, with higher tendency to drift for the former, which settled after drifting from $4 \mathrm{~m}$ on, and especially from 7 to $10 \mathrm{~m}$, whereas the settling abilities of Nemoura spp. did not change much with distance, with a higher percentage of nymphs still drifting after $10 \mathrm{~m}$, thus confirming the trend recorded by Lancaster et al. (1996). Isoperla spp., is common in drift and with weak swimming abilities (Poff et al., 2006) but had a low catastrophic drift rate in our flumes; similarly to Leuctra sp., this taxon tended to settle after $7 \mathrm{~m}$ drifting.

\section{CONCLUSIONS}

In this experiment, we simulated a point disturbance represented by a sediment movement that triggered catastrophic drift. In real case scenarios (such as floods, hydropeaking events) the disturbance is, however, diffuse. In previous experiments we conducted in the same flume system (Carolli et al., 2012; Bruno et al., 2013, 2016), we simulated hydropeaking or thermopeaking waves which elicited a drift response from the benthos occupying the entire flume substrate. Hence, the results of this and our previous studies cannot be compared. Nevertheless, as pointed out by Gibbins et al. (2007) field studies aimed at monitoring drift during periods of elevated discharge associated with sediment movement should correctly assess the point from which the drifting animals originate in order to distinguish between hydrological events that represent ecological disturbances (those resulting in catastrophic drift) and those that do not. We have shown, in accordance with numerous other studies, that entrained EPT nymphs travel only short distances before returning to the substratum, and that the actual distance travelled while drifting and the total time spent in drift varies between species.

On a large scale (i.e., stream length or reaches), these taxon-specific factors are important because they define the space/period over which a drifting invertebrate is available, for instance, to drift-feeding fish, or to recolonize previously depleted areas. On a smaller scale (i.e., 
flume simulations), the study can provide insights on how to extrapolate results obtained in artificial flume systems to support evidences from field studies.

\section{ACKNOWLEDGMENTS}

The authors wish to thank the Servizio Bacini Montani, Autonomous Province of Trento, for building and maintaining the flumes.

\section{REFERENCES}

Allan JD, Feifarek BP, 1989. Distances travelled by drifting mayfly nymphs: factors influencing return to the substrate. J. N. Am. Benthol. Soc. 8:322-330.

Barbour MT, Gerritsen J, Griffith GE, Frydenborg R, McCarron E, White JS, Bastian ML. 1996. A framework for biological criteria for Florida streams using benthic macroinvertebrates. J. N. Am. Benthol. Soc. 15:185-211.

Bond NR, Downes BJ, 2003. The independent and interactive effects of fine sediment and flow on benthic invertebrate communities characteristic of small upland streams. Freshwater Biol. 48:455-465.

Brittain JE, Eikeland TJ, 1988. Invertebrate drift. A review. Hydrobiologia 166:77-93.

Bruno MC, Cashman MJ, Maiolini B, Biffi S, Zolezzi G, 2016. Responses of benthic invertebrates to repeated hydropeaking in semi-natural flume simulations. Ecohydrology 9:68-82.

Bruno MC, Maiolini B, Carolli M, Silveri L, 2009. Hydropeaking impact on hyporheic invertebrates of an Alpine stream (Trentino, Italy). Ann. Limnol. - Int. J. Lim. 45:1-14.

Bruno MC, Siviglia A, Carolli M, Maiolini B, 2013. Multiple drift responses of benthic invertebrates to interacting hydropeaking and thermopeaking waves. Ecohydrology 6: 511-522.

Campaioli S, Ghetti F, Minelli A, Ruffo S, 1994. [Manuale per il riconoscimento dei macroinvertebrati delle acque dolci italiane. 1].[Book in Italian]. Provincia Autonoma di Trento, Trento: $357 \mathrm{pp}$.

Campaioli S, Ghetti F, Minelli A, Ruffo S, 1999. [Manuale per il riconoscimento dei macroinvertebrati delle acque dolci italiane. 2].[Book in Italian]. Provincia Autonoma di Trento, Trento: $484 \mathrm{pp}$.

Campbell RNB, 1985. Comparison of the drift of live and dead Baetis nymphs in a weakening water current. Hydrobiologia 126:229-236.

Carolli M, Bruno MC, Siviglia A, Maiolini B, 2012. Responses of benthic invertebrates to abrupt changes of temperature in flume simulations. Riv. Res. Appl. 28:678-691.

Céréghino R, Lavandier P, 1998. Influence of hypolimnetic hydropeaking on the distribution and population dynamics of Ephemeroptera in a mountain stream. Freshwater Biol. 40:385-399.

Ciborowski JJH, 1983. Downstream and lateral transport of nymphs of two mayfly species (Ephemeroptera). Can. J. Fish. Aquat. Sci. 40:2025-2029.

Ciborowski JJH, Corkum LD, 1980. Importance of behaviour to the re-establishment of drifting Ephemeroptera, p. 321330. In: J.F. Flannagan and K.E. Marshall (eds.), Advances in Ephemeroptera biology. Plenum Publ. Co.
Culp JM, Wrona FJ, Davies RW, 1985. Response of stream benthos and drift to fine sediment deposition versus transport. Can. J. Zool. 64:1345-1351.

Elliott JM, 1971. The distances travelled by drifting invertebrates in a Lake District stream. Oecologia 6:350-379.

Elliott JM, 2002. Time spent in the drift by downstream-dispersing invertebrates in a Lake District stream. Freshwater Biol. 47:97-106.

Fenoglio S, Boano F, Bo T, Revelli R, Ridolfi L, 2013. The impacts of increasing current velocity on the drift of Simulium monticola (Diptera: Simuliidae): a laboratory approach. Ital. J. Zool. 80:443-448.

Fochetti R, Tierno De Figueroa JM, 2009. [Plecoptera. 43. Fauna d'Italia].[Book in Italian]. Calderini, Bologna.

Fonseca DM, Hart DD, 2001. Colonization history masks habitat preferences in local distributions of stream insects. Ecology 82:2897-2910.

Gibbins CN, Scott E, Soulsby C, McEwan I, 2005. The relationship between sediment mobilisation and the entry of Baetis mayflies into the water column in a laboratory flume. Hydrobiologia 533:115-122.

Gibbins CN, Vericat D, Batalla RJ, Gomez CM, 2007. Shaking and moving: low rates of sediment transport trigger mass drift of stream invertebrates. Can. J. Fish. Aquat. Sci. 64:1-5.

Hieber M, Robinson CT, Uehlinger U, 2003. Seasonal and diel patterns of invertebrate drift in different alpine stream types. Freshwater Biol. 48:1078-1092.

Holomuzki JR, Biggs BJF, 2000. Taxon-specific responses to high-flow disturbance in streams: implications for population persistence. J. N. Am. Benthol. Soc. 19:670-679.

Imbert JB, Perry JA, 2000. Drift and benthic invertebrate responses to stepwise and abrupt increases in non-scouring flow. Hydrobiologia 436:191-208.

Lancaster J, Buffin-Bélanger T, Reid I, Rice S. 2006. Flow- and substratum-mediated movement by a stream insect. Freshwater Biol. 51:1053-1069.

Lancaster J, Hildrew AG, Gjerlov C, 1996. Invertebrate drift and longitudinal transport processes in streams. Can. J. Fish. Aquat. Sci. 4:572-582.

Larkin PA, McKone DW. 1985, An evaluation by field experiments of the McLay model of stream drift. Can. J. Fish. Aquat. Sci. 42:909-918.

Lenat DR, 1988. Water quality assessment using a qualitative collection method for benthic macroinvertebrates. J. N. Am. Benthol. Soc. 7:222-233.

Maier KJ, 2001. The influence of floods on benthic insect populations in a Swiss mountain stream and their strategies of damage prevention. Arch. Hydrobiol. 150:227-247.

McLay C, 1970. A theory concerning the distance travelled by animals entering the drift of a stream. J. Fish. Res. Board Can. 27:359-370.

Mochizuki S, Kayabam Y, Tanida K, 2006. Drift patterns of particulate matter and organisms during artificial high flows in a large experimental channel. Limnology 7: 93-102.

Oldmeadow DF, Lancaster J, Rice SP, 2010. Drift and settlement of stream insects in a complex hydraulic environment. Freshwater Biol. 55:1020-1035.

Otto C, 1976. Factors affecting the drift of Potamophylax cingulatus (Trichoptera) larvae. Oikos 27:93-100. 
Otto C, Sjöström P, 1986. Behaviour of drifting insect larvae. Hydrobiologia 131:77-86.

Poff NL, Olden JD, Vieira NKM, Finn DS, Simmons MP, Kondratieff BC, 2006. Functional trait niches of North American lotic insects: traits-based ecological applications in light of phylogenetic relationships. J. N. Am. Benthol. Soc. 25:730-755.

PRIMER-E Ltd., 2009. PRIMER 6.1.12: Plymouth routines in multivariate ecological research.

Rader RB. 1997. A functional classification of the drift: traits that influence invertebrate availability to salmonids. Can. J. Fish. Aquat. Sci. 54:1211-1234.

Resh VH, Jackson JK, 1993. Rapid assessment approaches to biomonitoring using benthic macroinvertebrate, p. 195-234.
In: D.M. Rosenberg and V.H. Resh (eds.), Freshwater biomonitoring and benthic macroinvertebrates Chapman and Hall, New York.

Silveri L, Tierno de Figueroa JM, Maiolini B, 2008. Feeding habits of Perlodidae (Plecoptera) in the hyporheic habitats of Alpine streams (Trentino - NE Italy). Entomol. Fenn. 19:176-183.

StatSoft, 2010. STATISTICA, data analysis software system, ver. 9.1. Available from: www.statsoft.com

Suren AM, Jowett IG, 2001. Effects of deposited sediment on invertebrate drift: an experimental study. New Zeal. J. Mar. Fresh. 35:725-737.

Townsend CR, Hildrew AG, 1976. Field experiments on the drifting, colonization and continuous redistribution of stream benthos. J. Anim. Ecol. 45:759-772. 